\title{
Investigation of the effect of a priming stimulus on backward masking'
}

\author{
Charles W. Eriksen and James F. Collins \\ UNIVERSITY OF ILLINOIS
}

\begin{abstract}
Using the backward masking paradigm of a form followed shortly after exposure by a ring, the effect of a priming stimulus appearing 100,50 , and $10 \mathrm{~ms}$. prior to the form was investigated. Although the backward masking effects were found, no effect of the priming stimulus was obtained.
\end{abstract}

\section{Introduction}

Eriksen \& Collins (1964) previously found that brief presentation of a ring stimulus following a brief exposure of a simple form, impaired the forced-choice recognition of the form even when the onset of the ring was delayed as long as $100 \mathrm{~ms}$. In subsequent work (Eriksen \& Collins, 1965) this masking effect was found to be symmetrical in that the same masking function was generated when a brief presentation of the ring stimulus p r e ceded the form stimulation. For both forward and backward masking, maximum recognition impairment was found when form and ring occurred concurrently, suggesting that masking consists of the greater difficulty in recognition of a form surrounded by a black ring than a form appearing in an uncluttered white field.

This interpretation accounts for the masking per se but moves the experimental problem forward to the question of how stimuli separated in time by as much as 100 ms. come to be perceived as though they had occurred simultaneously. Two possible mechanisms were advanced. One proposed possibility, similar to that proposed by other investigators (White \& Cheatham, 1959; Stroud, 1956), is that visual perception is organized on the basis of chunks of sensory inputs of between 50 and $100 \mathrm{~ms}$. in size. The second possibility advanced was that a second stimulus, if it follows a preceding stimulus within a short time duration, is facilitated in its transmission through the visual system. Thus it is capable of overtaking the preceding stimulus and being perceived simultaneously with it. The present experiment was a test of this latter possibility.

Reduced perceptual latency for a second stimulus was tested using the backward masking paradigm with modification. Forms of known recognition level were presented followed at brief time delays by a ring. In the present experiment an additional stimulus consisting of a light spot appeared simultaneously, 10,50, or $100 \mathrm{~ms}$. before the form stimulus and in the samelocation in the visual field. If this prior stimulation by the spot of light reduces the perceptual latency for the form stimulus at certain of these lead time intervals then the masking effect of the following ring stimulus ought to be eliminated or reduced. This assumes that the facilitation of preceding stimuli upon succeeding ones is essentially linear and that the spot reduces the perceptual latency for the form by approximately the same amount that the form reduces the perceptual latency of the ring. Method

A model GA Scientific Prototype three-field tachistoscope was used. Through the use of auxiliary timing circuits and a separate light source for backlighting, it was possible to arrange a stimulation sequence consisting of: a lighted adaptation field (.58 apparent foot candles) with an $\mathrm{H}$ fixation point $\left(.2^{\circ}\right)$; a priming stimulus consisting of a .42 apparent foot candle circle of light with a diameter of $.3^{\circ}$; a form; and a black masking ring stimulus. All stimuli were superimposed upon the luminance of the adapting field which remained on continuously. The form stimuli were the letters $\mathrm{A}, \mathrm{T}$, and $\mathrm{U}$, black on white and subtending $.2^{\mathrm{O}}$ of angle. The masking ring was also black on white and had an inner diameter of $.3^{\circ}$ and an outer of $.67^{\circ}$. Background luminance of both form and masking fields was .2 apparent foot candles.

Prior to beginning experimental sessions each $\mathrm{S}$ engaged in several sessions of practice during which his $85 \%$ correct forced-choice recognition accuracy for the three letter forms was determined under the condition where the priming stimulus occurred $100 \mathrm{~ms}$. before the form and the masking stimulus did not occur. The duration of exposure yielding approximately $85 \%$ recognition was then used for the particular $S$ as the exposure duration for the forms during the experimental sessions. The ring was always exposed at a constant $100 \mathrm{~ms}$. and the priming stimulus varied in duration depending upon its time of onset since it remained on through the remaining sequence of stimulation. There were two experimental conditions: ring present-the ring appeared either simultaneously with the occurrence of the form or at delays of 10,50 , or $100 \mathrm{~ms}$; ring absent-same as ring present except that an empty field having the same luminance as the ring field was substituted for the ring at the same delay intervals. In both conditions the priming stimulus appeared simultaneously with the form or at lead time intervals of 100,50 , or $10 \mathrm{~ms}$. before.

\section{Subjects}

Four paid undergraduates (three males) served for 18 experimental sessions each during which they had 40 trials under each priming stimulus interval by delay interval by ring present-absent condition.

\section{Results and Discussion}

Percent correct forced-choice recognitions were analyzed by a four-way analysis of variance (priming stimulus lead interval, ring delay interval, ring present- 


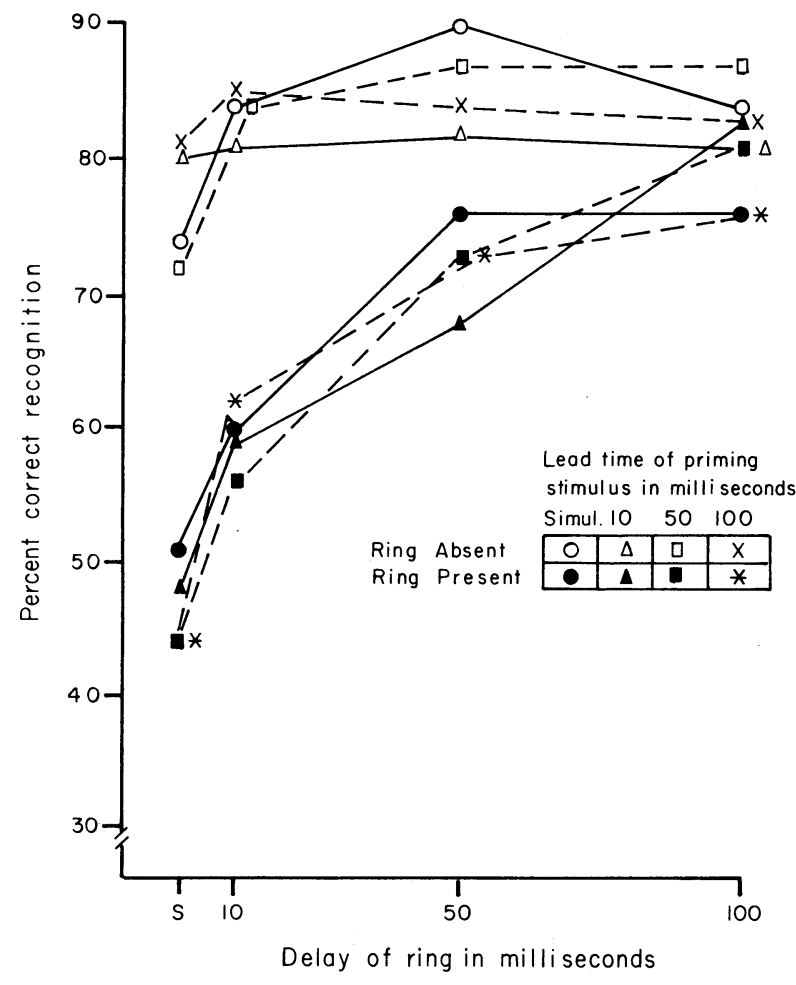

Fig. 1. Recognition as a function of ring present-absent conditions, lead time of priming stimulus and delay of masking ring.

absent condition, and Ss). Conditions, ring delay, and Ss were significant effects $(p<.01)$. However the effect of different lead times for the priming stimulus was not significant. As expected the interaction between ring present-absent conditions and delay of the masking ring was significant $(p<.01)$ but none of the other interactions including those involving the lead time of the priming stimulus approached significance.

In Fig. 1 recognition accuracy is shown as a function of ring present-absent conditions by delay interval of the masking ring. The parameters in Fig. 1 represent the different lead times of the priming stimulus. The masking effect of the ring stimulus even when delayed by $50 \mathrm{~ms}$. or more is quite apparent. Also maximum masking effects are again obtained when ring and form occur simultaneously. For the ring absent condition recognition accuracy remains constant indicating that the flash of the empty masking field has little or no effect upon recognition accuracy except under the simultaneous condition. Here there is a tendency for recognition accuracy to be slightly less due perhaps to luminance sum- mation between the form and masking field which reduces figure-ground contrast for the letter (Eriksen \& Steffy, 1964). Luminance summation may also account for some of the rather large difference in the amount of masking between the simultaneous and the $10 \mathrm{~ms}$. delay of the ring.

As is also apparent from Fig. 1 there is no systematic effect attributable to the priming stimulus whether it occurs simultaneously with the form or precedes it by as much as $100 \mathrm{~ms}$. under either condition. This would seem to rule out the possibility that a visual stimulus reduces the perceptual latency of a succeeding stimulus as an explanation of how two stimuli separated by brief intervals of time are treated perceptually as though they had occurred together. As previously reported (Eriksen \& Collins, 1965) forward and backward masking under this experimental arrangement were found to give essentially the same masking function. In forward masking where the ring occurs first the retinal area to be stimulated by the succeeding form receives first a circular light stimulus corresponding to the center of the ring. The priming stimulus in the present experiment duplicated this stimulation. Thus it would seem that this priming stimulus would have been adequate to produce the reduction of perceptual latency for the succeeding form if such a quickening mechanism was operating.

The present results under a broader range of stimulus conditions confirm our previous findings with respect to backward masking. If a correction is made in the present data for the difference in level of recognition accuracy $(85 \%$ as opposed to $70 \%)$ and the longer exposure duration this entailed, the data points fit quite well along the backward masking function previously described.

\section{References}

ERIKSEN, C. W., \& COLLINS, J. F. Backward masking in vision. Psychon. Sci., 1964, 1, 101-102.

ERIKSEN, C. W., \& COLLINS, J. F. A reinterpretation of one form of backward and forward masking in visual perception. J. exp. Psychol., in press.

ERIKSEN, C. W., \& STEFFY, R. A. Short term memory and retroactive interference in visual perception. J. exp. Psychol., in press.

STROUD, J. M. The fine structure of psychological time. In H. Quastler (Ed.), Information theory in psychology. Glencoe, Ill.: Free Press, 1956, Pp. 174-207.

WHITE, C. T., \& CHEATHAM, P. G. Temporal numerosity: IV. A comparison of the major senses. J. exp. Psychol., 1959, 58, 441-444.

\section{Note}

1. This research was supported by grants USPH M-1206 and USPH Research Career award K6 MH-22014. 